\title{
THE PHOSPHATASE ACTIVITY IN SPONDYLITIS ANKYLOPOIETICA
}

\author{
BY \\ M. H. L. DESMARAIS \\ Sydney Robinson Research Fellow, Royal Mineral Water Hospital, Bath
}

\section{Introduction}

Ankylosing spondylitis is at present a disease of unknown aetiology and many theories have been put forward as to its origin. Buckley (1945) reviewed a mass of evidence bearing on a possible biochemical mechanism which involves serum phosphatase as a cardinal factor in producing the abnormal ligamentous calcification and the bony changes which constitute the main pathological features of the disease. Batson (1940), investigating the spread of carcinoma of the prostate to the sacro-iliac regions and spine, suggested that the venous plexus connecting the prostatic veins with the prevertebral veins might well be the route of spread of metastases. Cunningham (1937) described a venous plexus between the periosteum and spinal canal. These veins, being without valves, may produce stagnation of blood in these regions and cause meningeal irritation. Ludwig and others (1943) reported an increase of protein and abnormal Lange curves in forty-two cases based on a study of 101 cases of spondylitis ankylopoietica.

The prostate contains a very active phosphatase. This phosphatase can be estimated in the blood as it has its optimum activity at a $p \mathrm{H}$ of 4.9. Normal amounts lie between 1 and 3 units. Gutman and Gutman (1938) found that very large amounts of acid phosphatase may appear in the blood in carcinoma of the prostate with secondaries in the bones. McWhirter (1945), considering that a leakage of prostatic acid phosphatase into the prevertebral veins may be an aetiological factor in the production of spondylitis, investigated the acid serum phosphatase in seven patients and found a raised level in cases in which the disease was at an early stage. Shorvon and Pearson (1937) reported a raised acid phosphatase in one early case of several cases investigated, but did not give the total number of cases under review. Race, quoted by Buckley (1945), estimated the acid phosphatase in thirteen cases and found that the average level was $2 \cdot 2$ units (normal 4 units). The highest figure was 3.8 and the lowest 0.9 units, and Race concluded that acid phosphatase probably had no bearings on ankylosing spondylitis. In a series of cases reported by him in 1945 Buckley found a slight increase in the alkaline phosphatase, the average being $\mathbf{0 . 3 5}$ (Kay units) compared with the normal maximum of 0.2 units. Race, in 1932, estimated the alkaline phosphatase in sixteen cases and reported a slight rise, between 0.21 and 3.6 units in seven cases (43.7 per cent). Normal $0 \cdot 11$ to $0 \cdot 19$ (Kay units).

In view of the conflicting reports as to the value of estimating the alkaline and acid phosphatase in

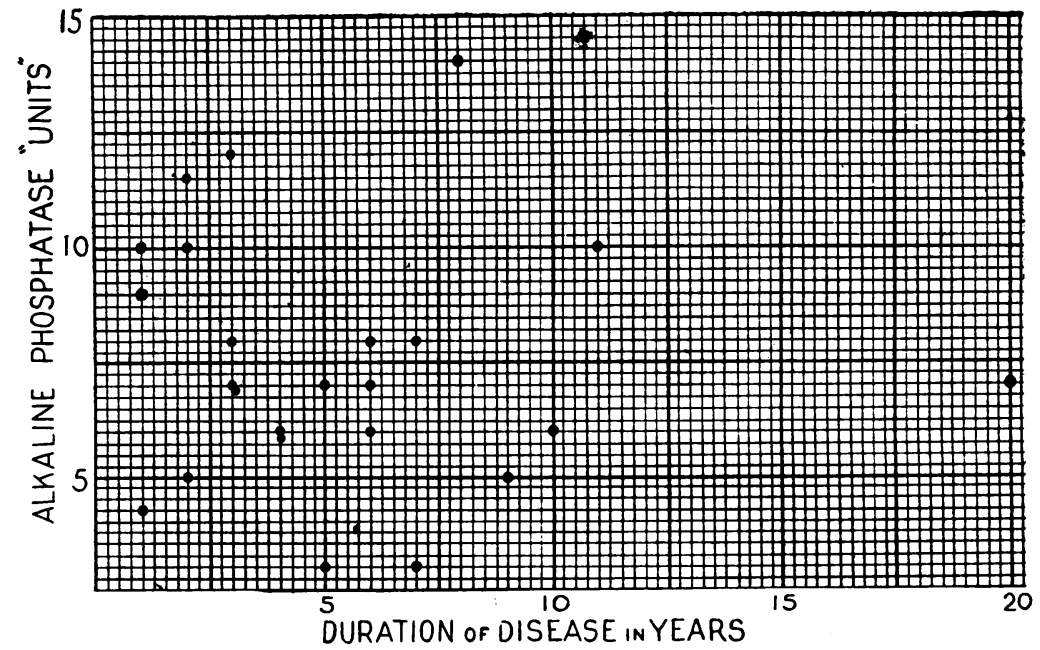

Fig. 1.-Scatter diagram showing lack of correlation between duration and alkaline phosphatase. 


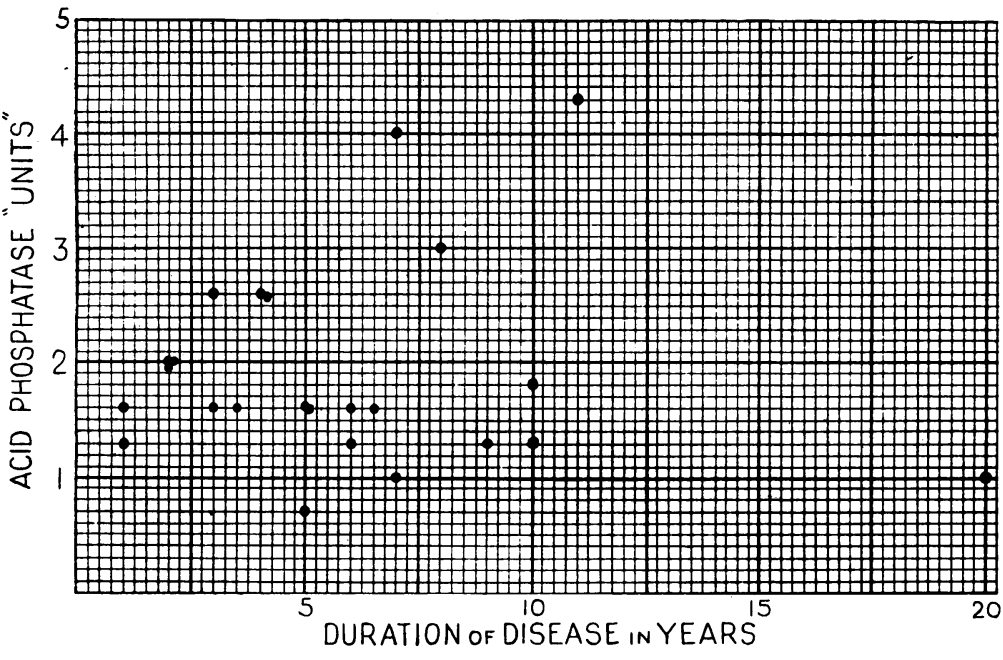

FIG. 2.-Scatter diagram showing lack of correlation between duration and acid phosphatase.

cases of spondylitis ankylopoietica and the different methods used, a series of twenty-four cases was investigated.

\section{Method}

The method used was King's (1946) modification of King and Armstrong. It depends on the amount of phenol set free when the enzymes are allowed to act on an ester of phosphoric acid such as phenyl phosphate at an optimum $p \mathrm{H}$. The normal levels by this method are 5 to 10 units and 1 to 3 units for the alkaline and acid phosphatases respectively. diagrams showing the lack of correlation between the alkaline and the acid phosphatase and the activity of the disease. The sedimentation rate is a good index of activity, being raised in the active stage and tending to reach normal as the condition becomes arrested.

\section{Discussion}

Osteoporosis is an early recognizable change in spondylitis. This may be associated either with an increase osteoclastic activity or a reduced osteoblastic action in the bone. As a result of the bone-softening it is possible that the calcification which takes place in the fibrous and fibro-cartilaginous structures round the affected joints may be an attempt at splinting the softened bones to prevent deformity.

Sclerosis, an early radiological change in the sacro-iliac and intervertebral joints is usually associated with relatively low values of serum phosphatase activity, whereas in osteoporosis of rickets the phosphatase is consistently raised and tends to return to normal during antirachitic therapy (Bodansky and Jaffe, 1934). These three antagonistic processes of osteoporosis, osteosclerosis,

\section{Results}

The average alkaline phosphatase level was $6 \cdot 2$ units. The highest level was 14 units and the lowest 3 units. Only three cases ( 12.5 per cent.) gave a high normal reading.

The average acid phosphatase activity was 1.75 units with the highest level at 4.3 and the lowest at 0.7 units. In this series two cases $(8 \cdot 5$ per cent.) gave a high normal reading.

From Figs. 1 and 2 it can be seen at a glance that there is no correlation between the duration of disease in years and the alkaline and acid phosphatase activity.

Figs. 3 and 4 are scatter

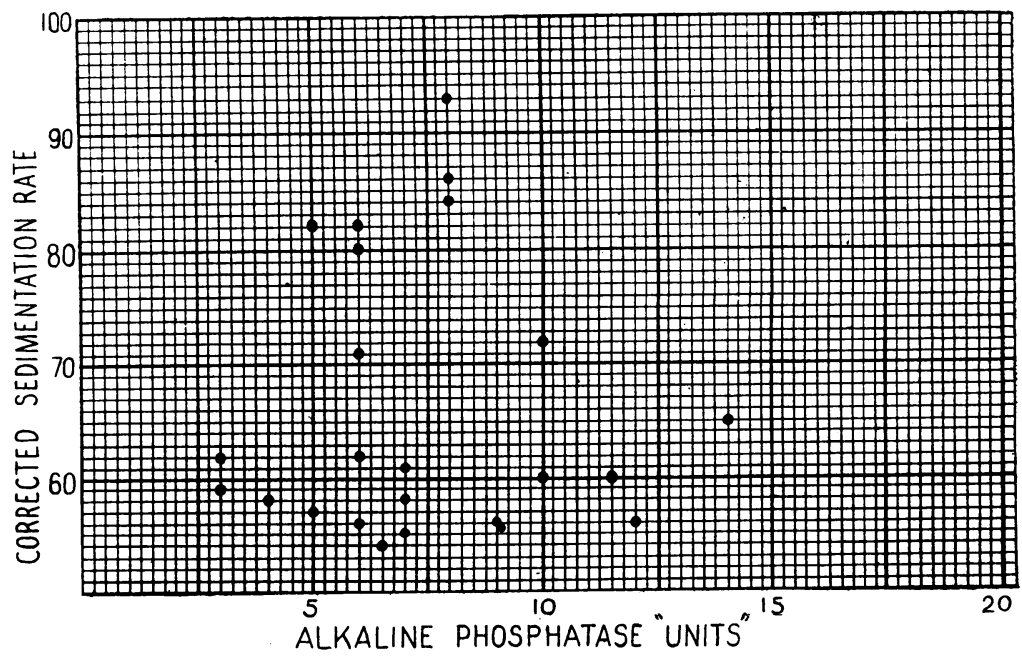

FIG. 3.-Scatter diagram showing lack of correlation between corrected sedimentation rate and alkaline phosphatase. 


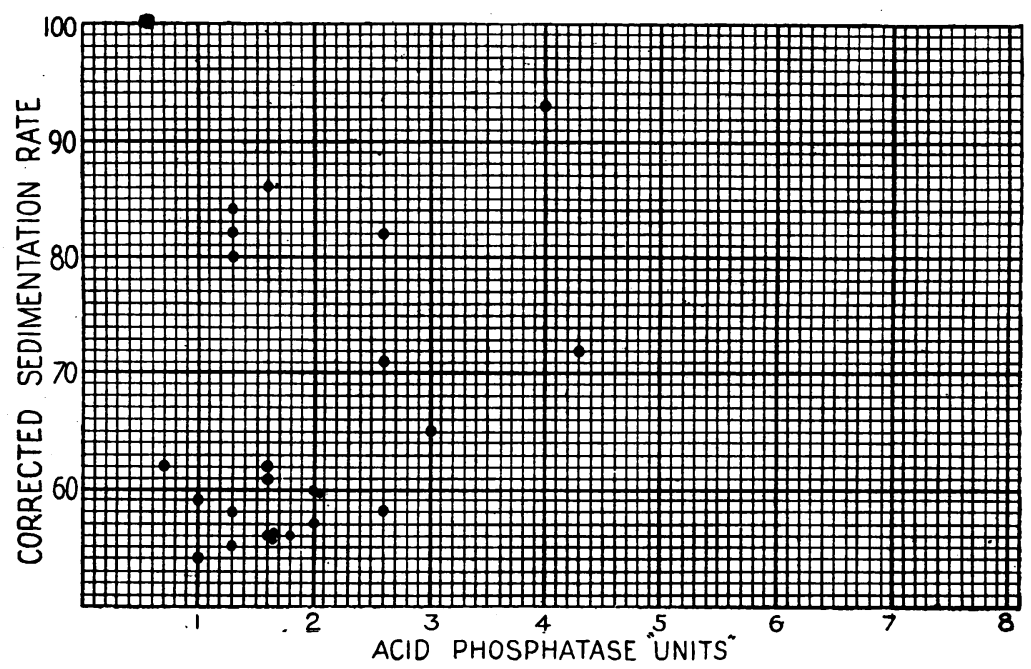

FIG. 4.-Scatter diagram showing lack of correlation between C.S.R. and acid phosphatase.

and calcification of ligaments taking place simultaneously may be the cause of frequent normal values for the serum phosphatase, and the occasional high values reported may be due to the predominence of osteoblastic activity at the time of estimation. There is also some evidence that senility, malnutrition, and anaemia tend to lower the serum phosphatase activity (Cantarow and Trumper, 1945); and the influence of the parathyroid hormone, thyroxin, vitamin $D$, and absorption of calcium from the bowels should be borne in mind in interpreting the complicated processes of calcium metabolism.

\section{Summary}

1. The literature on the estimation of serum phosphatase in spondylitis ankylopoietica is reviewed.

2. The relation between alkaline and acid phosphatase and the duration and activity of the disease is discussed.

3. It is suggested that the simultaneous and directly opposite processes of osteoporosis on the one hand, and sclerosis with abnormal calcification of ligaments on the other, are a cause of the frequent normal values for the serum phosphatase activity.

I wish to express my indebtedness to E. W. Richardson, Laboratory Technician at the Royal National Hospital for Rheumatic Diseases, Bath, for his help in carrying out the estimations.

\section{REFERENCES}

Batson, O. V. (1940). Ann. Surg., 112, 138.

- (1942). Amer. J. Roentgen., 48, 715.

Bodansky, A., and Jaffe, H. L. (1934). Amer. J. Dis. Child., 48, 1268.

Buckley, C. W. (1945). Annals of the Rheumatic Diseases, 5, 49.

Cantarow, A., and Trumper, M. (1945). “Clinical Biochemistry." W.B. Saunders and Co., Philadelphia.

Cunningham, D. J. (1937). "Text Book of Anatomy." Oxford Medical Publications, pp. 1258 and 1267.

Gutman, A. B., and Gutman, E. B. (1938). J. clin. Invest., 17, 473.

King, E. J. (1946). " Micro Analysis in Medical Biochemistry." J. and A. Churchill, London.

Ludwig, A. O., Short, C. L., and Bauer, W. (1943). New Engl. J. Med., 228, 306.

McWhirter, R. (1945). Brit. J. Radiol., 18, 302.

Race, J. (1932). Arch. med. Hydrol. Lond., 10, 6.

Shorvon, L. M., and Pearson, Ruth (1947)!' Practitioner, 158,418 .

\section{Activité des Phosphatases dans la Spondylite Ankylosante RÉSUMÉ}

1. Revue bibliographique sur le dosage de la phosphatase dans la spondylite ankylosante.

2. Discussion sur le rapport entre la teneur en phosphatase alcaline et en phosphatase acide et la durée et la gravité de la maladie.

3. L'auteur suggère que les processus simultanés et directement opposés d'ostéoporose d'une part, et de sclérose avec calcification anormale des ligaments de l'autre, sont responsables des valeurs fréquemment normales de l'activité phosphatasique du sérum. 